\title{
Voter uncertainty and failure of Duverger's law: an empirical analysis
}

\author{
Michael Herrmann
}

\begin{abstract}
Real-world simple plurality elections rarely bear out the strong Duvergerian prediction that, in equilibrium, only two competitors receive votes. Recent advances in strategic voting theory demonstrate that voter uncertainty about competitors' true support levels in the constituency may lead to limited strategic voting, and hence incomplete desertion of trailing parties. This is the first attempt to estimate empirically the impact of uncertainty on incentives to vote strategically. Calibrating a model of strategic voting to voting results from simple plurality elections in German constituencies, it is found that strategic voters operate under high levels of uncertainty. These results support the proposition that uncertainty about party support impedes formation of Duvergerian equilibria.
\end{abstract}

Keywords Strategic voting · Duverger's law · Uncertainty · Voter information · Incumbency · German elections

\section{Introduction}

One of the most puzzling findings in the literature on strategic voting is that we often fail to observe two-party competition, despite abundant evidence for strategic voting in real-world plurality elections. This is puzzling because it is by now conventional wisdom that strategic voting should work to reduce the number of competitors in a simple plurality election to two. Specifically, when applied to single member constituencies, Duverger's law entails strategic coordination of supporters of weaker parties on the two front-runners (Cox 1997). While empirical research strongly suggests the presence of strategic voting, inspection of constituency level results at the same time

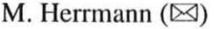

Lehrstuhl für Methoden der empirischen Politik- und Verwaltungsforschung, Universität Konstanz, Postfach 92, Universitätsstraße 10, 78457 Konstanz, Germany

e-mail: michael.herrmann@uni-konstanz.de 
reveals that simple plurality elections rarely bear out the strong Duvergerian prediction. ${ }^{1}$

This state of affairs is somewhat discomforting because what is considered by many as the distinctive virtue of the simple plurality election system, the pressure toward a twoparty system, critically rests on the assumption of potentially large scale strategic voting at the constituency level. If strategic voting fails to drive down the number of competitors significantly, then parties and candidates will not fear severe losses from entering or staying in the electoral race and multipartism will prevail. Given the alleged strengths of two-party systems in promoting government stability (Warwick 1994), accountability (Powell 2000), and fiscal discipline (Persson et al. 2007; Austen-Smith 2000), it is important to examine the reasons why voter coordination often fails to produce strict two-party competition.

This paper explores one reason for coordination failure that has drawn greater attention in the recent theoretical literature on strategic voting: the extent of voter uncertainty about the electoral outcome. To vote for a candidate that is not one's first preference obviously makes sense only if one can be sure that the preferred candidate is out of the running. Without common knowledge of who is trailing in the electoral race, voter coordination on two candidates is unlikely to succeed. Public opinion polls should, in theory, provide the information necessary for voters to coordinate, yet they are rarely if ever available at the level of constituencies. Uncertainty about party support may thus play a key role in impeding strategic coordination in real-world elections. This paper presents the first estimates of voter uncertainty from an empirical analysis of voting in simple plurality elections. The results suggest very high levels of uncertainty about the electoral outcome.

Extant game-theoretic treatments of strategic voting predict complete desertion of parties expected to come in third in a simple plurality election (Palfrey 1989; Myerson and Weber 1993; Cox 1994; Fey 1997). In what is commonly termed a "Duvergerian equilibrium,' voting behavior gives rise to a steady state in which only two parties receive votes. An important assumption underlying the Duvergerian equilibrium argument is that the distribution of voter preferences is known by all voters. Thus, by the law of large numbers and although individual preferences are unknown, a voter may predict the outcome of the election with near certainty. Given that the outcome is common knowledge, voters then expect some supporters of the likely loser (the party in third place) to vote for the lesser of evils among the two viable contenders. Such expected desertion further damages the trailing party's prospects of winning, and hence causes more voters to desert that party. Positive feedback continues this way, ensuring a strict two-party outcome in equilibrium. $^{2}$

Despite the strong equilibrium prediction, third party desertion is usually far from complete in actual mass elections. As a prime example, consider British parliamentary elections:

\footnotetext{
${ }^{1}$ For empirical evidence on strategic voting, see, e.g., Cain (1978), Galbraith and Rae (1989), Johnston and Pattie (1991), Ordeshook and Zeng (1997), Blais et al. (2005), Alvarez et al. (2006), and for empirical evidence on the number of parties in single member constituencies being generally greater than two, see, e.g. Gaines (1999), Cox and Schoppa (2002), Diwakar (2007), Grofman et al. (2009).

${ }^{2} \mathrm{~A}$ second type of equilibrium arising from this literature is a so-called non-Duvergerian equilibrium; a state in which the two challengers obtain exactly the same number of votes (see Palfrey 1989; Cox 1997). As Fey (1997) shows, however, these equilibria are highly unstable, and thus not predictive of real-world electoral outcomes.
} 
Since World War II English constituencies have been contested by the same three major parties, Conservative, Labour, and Liberal Democrat, yet it would be unreasonable to assert any form of convergence in electoral outcomes to something like Duvergerian equilibrium. The third placed party, no matter what color, retains sizable levels of support in the constituency despite incentives for strategic voting. The United Kingdom is just one example but similar conclusions can be drawn from considering election outcomes in Canada, India, and prereform New Zealand (cf. Chhibber and Kollman 1998; Gaines 1999; Cox and Schoppa 2002; Diwakar 2007; Grofman et al. 2009).

Recent contributions to strategic voting theory suggest that the absence of Duvergerian equilibria might be due to voter uncertainty about parties' true support levels in the constituency. Myatt (2007), studying a game-theoretic model of strategic voting in which voters must rely on private signals to form an estimate about the underlying distribution of voter preferences, argues that the prediction of strict two-party outcomes is driven by the assumption that voters know the distribution of party support in the constituency. Relaxing the assumption that the distribution of voter preferences is common knowledge, he shows that uncertainty about true party support results in negative feedback, which limits strategic voting and gives rise to equilibria characterized by incomplete desertion of third placed parties. In this model, voters' relative information levels determine their likelihood of casting strategic votes. With little information, strategic voters run the risk of deserting their preferred party even though it still has a fair chance of winning. Furthermore, what drives the equilibrium result is that voters expecting strategic switching by others become more cautious about voting strategically themselves - a negative feedback loop leading away from the Duvergerian equilibrium path. Experimental evidence also elucidates the importance of voter information for strategic voting and Duverger's law: Felsenthal et al. (1988) show that strategic coordination on two candidates is very likely in plurality elections when voters have complete information about others' preferences and voters with the same preferences are allowed to act in concert. Forsythe et al. $(1993,1996)$, studying elections in which voters must make decisions in isolation, show that polls are necessary in facilitating strategic coordination on two viable candidates (see also Rietz et al. 1998). In particular, polls help voters in identifying the two leading candidates which then become focal in the subsequent election. Without polls, coordination on Duvergerian outcomes usually fails. As these analyses show, the propensity of strategic coordination hinges critically on voter information levels. When the outcome of the election can be predicted with little uncertainty, strategic voting is feasible and will drive down the number of viable competitors. However, when voters have only vague knowledge about the likely outcome of the election they should be cautious not to desert their preferred alternative too easily because it may fare better than the information at hand predicts.

In this paper, the extent of voter information is assessed in simple plurality elections based on official voting records of single member constituencies in East Germany. In these elections, voters are given two votes, one for the constituency election and another which is allocated nationally according to proportional representation. Since votes do not pool or transfer between ballots, the voter's choice in the constituency contest is that of a plain plurality election. Comparing results from the plurality election with the distribution of votes cast under proportional representation in each district thus provides a unique opportunity for studying incentives for strategic voting and the degree of uncertainty voters face toward them. To that end, a statistical framework is developed based on a theoretic model by Myatt and Fisher (2002). The model is decision-theoretic, yet it fully captures the game-theoretic prediction that strategic voting should decrease as voters become more uncertain about the electoral situation. The findings suggest that voters operate under high levels of uncertainty. 
Apart from this result the statistical analysis also yields an unusually rich set of insights into many vital aspects of plurality elections, such as the direction and magnitude of strategic vote transfers between parties, the overall scope of strategic voting, its variability across districts, and the decisiveness of strategic voting for election outcomes. Although there are many published estimates of the extent of strategic voting at the national level, to the best of my knowledge, no other empirical study has ever provided detailed estimates of strategic vote transfers at the constituency level. This is remarkable, since it is only at the constituency level that strategic voting can become politically relevant.

The next section briefly outlines the general strategic voting model and highlights the role of uncertainty in voter decision making. Section 3 presents the empirical test case and Sect. 4 derives a statistical model of strategic voting in three-party simple plurality elections. Findings are presented in Sect. 5. The paper concludes with a discussion of how the results might give some hints on the extent to which strict two-party outcomes can be expected in real-world elections.

\section{The strategic voting model}

Strategic voting theory asserts that voters seek to cast their ballots so as to have the greatest impact on the election's outcome. While strategic voting comes in many different flavors, depending on context, my concern here is with the classic case of first-past-the-post (FPTP) elections. In a three-party plurality election, the voter's decision problem amounts to voting for the most preferred option versus casting votes for his or her second preference. The decision criterion for strategic voting is given by the well-known inequality

$$
2 p_{12}\left(u_{1}-u_{2}\right)+p_{13}\left(u_{1}-u_{3}\right)-p_{23}\left(u_{2}-u_{3}\right)<0
$$

(see McKelvey and Ordeshook 1972; Black 1978; Ordeshook and Zeng 1997), where subscript numbers denote a voter's first, second, and third preferred party, $u$ the utility a voter assigns to a given party, and $p$ is the probability of casting a decisive (pivotal) vote between two parties (i.e., the probability that the two parties are tied for the lead). ${ }^{3}$ Rearranging and parsing voter preferences from their expectations in (1) yields a more intuitive version of the strategic voting criterion:

$$
\log \frac{u_{1}-u_{3}}{u_{2}-u_{3}}<\log \frac{2 p_{12}+p_{23}}{2 p_{12}+p_{13}}
$$

(see Hoffman 1982; Palfrey 1989; Fey 1997; Fisher 2004). ${ }^{4}$ Equation (2) states that a voter will cast a strategic vote if the relative likelihood of influencing the election outcome by casting a second rather than a first choice vote (the right-hand side ratio) outweighs her relative preference for the first over the second choice party. In behavioral terms, the utility ratio represents the internal dispositions an individual carries to the voting booth, while the ratio of pivot probabilities captures outside "pressures" on the voter: the need to consider a second best alternative in order not to waste one's vote. In the following, we refer to

\footnotetext{
${ }^{3}$ For example, $p_{23}$ is the probability that the election result will be (one vote short of) a draw between a voter's second and third preferred party, while $p_{13}$ denotes the probability that the election will be (one vote short of) a tie between her first and third preferred party.

${ }^{4}$ To obtain (2) directly from (1), apply the affine transformation by subtracting $u_{3}$ from each of the individual $u$ terms, expand the first product and collect the utility differences.
} 
the (log) ratio of pivot probabilities as the voter's "strategic incentive." From (2), it can easily be seen that, holding relative preferences constant, the likelihood of a strategic vote should increase with the strategic incentive, i.e., the chance of deciding the election by casting a second preference vote. The ratio of pivot probabilities thus fully captures the competitive environment a voter faces in her constituency and it is the determination of pivot probabilities, where uncertainty about the election outcome comes into play.

\subsection{Voter uncertainty}

In game-theoretic models, most notably the model of Palfrey (1989), the election outcome is assumed to follow a multinomial distribution with parameters $p_{j}$ denoting the probability that a randomly selected individual will support party $j$. The parameters $p_{j}$ are assumed to be known to the voter so that, for each voter, the election outcome corresponds to a draw from a multinomial distribution with known parameters. This set up does not allow for uncertainty in voter expectations about the election outcome because in large electorates, such as constituencies in parliamentary elections, expected party vote shares quickly converge to parties' true support levels and hence any uncertainty is averaged out. Hoffman (1982) first addressed voter uncertainty in voter expectation formation by representing outcome probabilities via a Gaussian density over the outcome space. Unlike the multinomial, a Gaussian distribution allows for variance in the distribution of possible election outcomes even as the electorate grows large. Hoffman demonstrates that, as the variance in the possible election outcomes increases, the incentive for an individual to vote strategically wanes.

Myatt and Fisher (2002) make significant progress in building the notion of voter uncertainty into strategic voting theory. Departing from previous approaches, the authors propose a model that relaxes the assumption that voters know the distribution of party preferences in the constituency. In this model, the parameters governing the distribution of electoral support (i.e., the probabilities, $p_{j}$ ) are unknown to the voter. In effect, voters do not know how large or small of a fraction of individuals in their constituency supports each of the parties; instead they are assumed to draw on local information sources to infer the distribution of other voters' preferences and inform their decision. ${ }^{5}$ Based on their information, voters form beliefs about party support in the constituency and this, in turn, affects their judgment about the relative likelihoods of casting a decisive vote. As a result, the more information voters gather (or equivalently, the better the sources of information available to them) the better they are able to predict the outcome of the election and vote optimally.

Formally, the authors invoke a model of Bayesian learning about the parameters of a target distribution by way of sampling from this distribution. Let $y$ denote a vector whose elements $y_{j}$ denote the number of individuals supporting party $j \in\{1,2,3\}$ in a randomly drawn sample of voting intentions, such that $\sum_{j=1}^{3} y_{j}=s$; let $\pi_{j}=y_{j} / s$ denote the proportion of voters supporting party $j .{ }^{6}$ Assemble the individual parameters $p_{j}$ into the probability vector $p$ and the elements $\pi_{j}$ into the vector $\pi$. Starting from a uniform Dirichlet prior, the authors show that Bayesian updating, upon observing a random sample of $s$ voting intentions from a multinomial distribution, results in the following Dirichlet posterior beliefs

\footnotetext{
${ }^{5}$ Obviously, one good source of information, albeit rarely available at the constituency level, would be a representative poll. Apart from actual polls, local media reports might also provide hints about parties' popular support; even casual conversation with peers and other acquaintances might serve as potential sources of information to the individual voter.

${ }^{6}$ By definition, $\pi_{1}+\pi_{2}+\pi_{3}=1$.
} 
Fig. 1 Precision of voter beliefs $s$ and the strategic incentive for different electoral scenarios. Values indicate expected vote shares of 1st, 2nd, and 3rd preferred party. As $s$ increases, voters become more certain of the electoral situation and the incentive to vote strategically grows (if the preferred party is trailing) or wanes (if the preferred party fares better than third place)

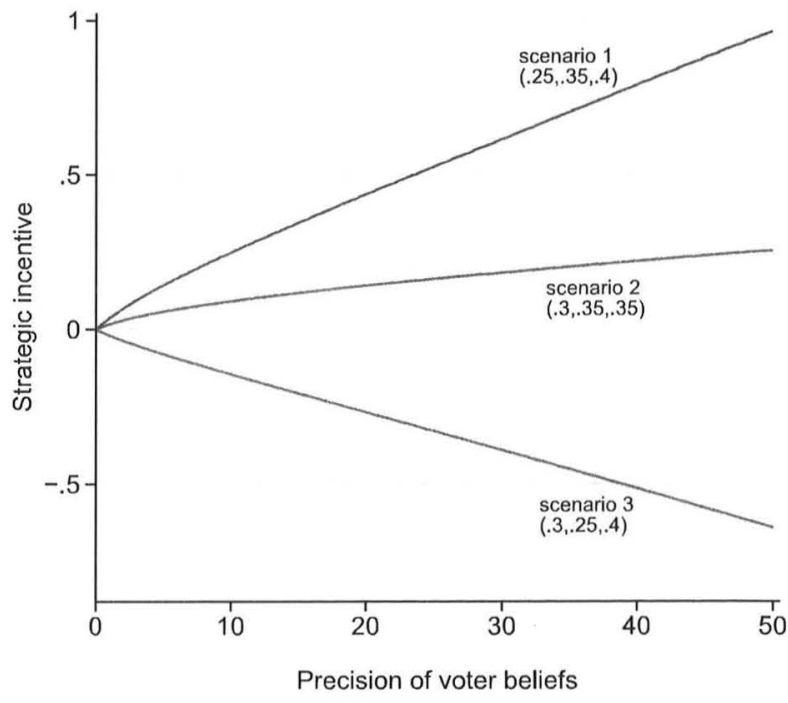

about the true party support, $p$, in the constituency:

$$
f(p \mid y) \propto\left[\prod_{j=1}^{3} p_{j}^{\pi_{j}}\right]^{s} .
$$

Two properties of these beliefs are important for understanding strategic behavior: First, the mode of the distribution is given by the vector $\pi$. For the voter, the most likely distribution of party support therefore corresponds to the vote shares of the three parties, $\pi_{j}$, in her given sample. Second, the variance of her beliefs decreases in $s$. The more voting intentions the voter observes the more certain she becomes in predicting the outcome because the distribution of possible outcomes concentrates more and more around its modal value. Her beliefs about actual party support in the constituency thus become increasingly precise as the size of her private sample, $s$, grows. ${ }^{7}$

Based on the posterior beliefs in (3), Myatt and Fisher derive a closed-form expression for the strategic incentive under uncertainty. Accordingly, a voter's incentive to defect from first to second preference, $\log \frac{2 p_{12}+p_{23}}{2 p_{12}+p_{13}}$, can be expressed as

$$
I_{12}(s)=\log \frac{B_{1 / 3}\left(1+\pi_{3} s, 1+\left(1-\pi_{3}\right) s\right)+2^{\left(\pi_{1}-\pi_{3}\right) s-1} B_{1 / 3}\left(1+\pi_{1} s, 1+\left(1-\pi_{1}\right) s\right)}{B_{1 / 3}\left(1+\pi_{3} s, 1+\left(1-\pi_{3}\right) s\right)+2^{\left(\pi_{2}-\pi_{3}\right) s-1} B_{1 / 3}\left(1+\pi_{2} s, 1+\left(1-\pi_{2}\right) s\right)},
$$

where $B_{1 / 3}(\cdot)$ is the incomplete Beta function, evaluated at $\frac{1}{3}$, with given parameters and the terms $\pi_{j}$ denote the fractions of voters who support one of the three parties, where parties are numbered according to their position in the voter's preference ranking.

To illustrate how the strategic incentive depends on voter information levels, consider the three scenarios depicted in Fig. 1. For a voter in a potentially strategic situation, i.e., whose first prefierence party is expected to come third in the electorate contest, as in scenarios

\footnotetext{
${ }^{7}$ As a consequence of the law of large numbers, the observed support converges in probability to the true support as $s \mapsto \infty$ so that, in the limit, voters would be able to predict the outcome with near certainty.
} 
1 and 2, the incentive to cast a strategic vote grows the more certain the voter becomes of that result. ${ }^{8}$ With less certainty, however, her incentive to defect from first preference decreases as the chances of a tie for the lead between the top two contenders become similar to chances of a tie between any other pair of parties. Scenario 2 reveals that, with equal degrees of uncertainty, a voter has less of an incentive to defect if her preferred choice is expected to trail only by a small difference. Still the strategic incentive grows as voters become more certain about the election result, albeit at a lower rate than in the previous scenario. In scenario 3, the strategic incentive is negative for a voter whose preferred party is expected to come in second place behind the most disliked alternative. In this situation, it is rational to vote sincerely because the perceived chance of a tie for victory between one's first and third preferred party is greater than that of a tie between the second and third preference parties. As with the other cases, greater certainty in voter beliefs makes that reasoning even more evident. As the examples illustrate, voter information may be crucial for electoral coordination and strategic voting because it shapes the way voters judge parties' underlying levels of support, and hence the relative likelihoods of pivotal events. Because uncertainty dampens voter responsiveness, in real-world elections, we may see incomplete desertion of third placed parties, even in very large electorates.

\section{Estimating voter uncertainty: East Germany as a test case}

In the following, the extent of voter uncertainty is explored by estimating the precision of voter beliefs (i.e., the value of $s$ ) about party support in single seat elections. To that end, one requires data on the constituency-wide support for every party as well as the extent of strategic voting. In pure FPTP elections, such as British General Elections, it is difficult to obtain measures of party support net of strategic voting. Mixed electoral systems, which combine simple plurality rule with elements proportional representation, allow one to identify more easily strategic voting from actual party support in the constituency. Employing simultaneous plurality-proportional representation-voting for more than half a century now, Germany is commonly referred to as the prime example of a mixed electoral system.

The German electoral system provides voters with two votes, a so-called first vote, Erststimme, for a party candidate in a single seat constituency election and a second vote, Zweitstimme, for a party list, which is aggregated nationwide to determine parties' seat shares in parliament according to proportional representation (PR). Votes do not pool or transfer between ballots, so any first vote cast on a hopeless candidate in the constituency election is essentially wasted. Second votes, on the other hand, are not easily wasted on minor parties, due to their proportional allocation at the national level. It is thus possible to treat the second vote as a measure of voters' sincere preferences (see below for a more extensive explanation). Given the predominance of parties in German electoral history it appears safe to assume that first vote balloting is guided by candidate party membership and only to a minor degree by specific candidate characteristics. Thus, unlike pure FPTP systems the German two-vote system with simultaneous plurality and PR voting makes it possible to separate party support from actual (strategic) voting under simple plurality rule.

The theoretical predictions presented in Sect. 2 assume a three-party contest. Constituency elections in East Germany between 1994 and 2005 provide such a context for empirical testing. In these four elections, gross voter support in East Germany was split

\footnotetext{
${ }^{8}$ Note that greater certainty about the expected outcome still implies that pivot probabilities remain nonzero, even though they may get arbitrarily small.
} 
Table 1 The absence of bipartisan outcomes in East German constituencies

\begin{tabular}{lllll}
\hline & & 1994 & 2002 & 2005 \\
Avg. vote share (\%) by order of finish & $18 \%$ & $20 \%$ & $18 \%$ & $23 \%$ \\
Avg. vote share of 3rd place finisher & $12-27$ & $12-28$ & $13-25$ & $14-28$ \\
(min.-max.) & 71 & 70 & 57 & 56 \\
No. of constituencies & & &
\end{tabular}

In a Duvergerian equilibrium, only the first two candidates in each district should get some votes. As the histograms show, however, votes in East German constituencies concentrate on the first three candidates. The numbers below the histograms further confirm that candidates in third place consistently perform better than one would expect under complete strategic voting

mainly between three parties, the Christian Democrats (CDU), the Social Democrats (SPD), and the Democratic Socialists/Left Party (PDS). Together, these three parties won, on average, about $90 \%$ of the vote, finishing either first, second, or third in almost every constituency. ${ }^{9}$ Unlike West Germany-where the CDU and the SPD win the lion's share of constituency votes and support for third party candidates is splintered among supporters of the Liberal Democrats (FDP), the Green party, and the PDS - East Germany, in the sample period, features essentially three competitive parties (cf. Herrmann and Pappi 2008). ${ }^{10}$

Under the prediction of Duvergerian equilibrium, one would expect strategic voting to drive down the number of competitors so that, in equilibrium, only two parties receive first votes in each district. According to Table 1, this is not the case-bipartisan outcomes do not occur in East Germany. Even if one finds the strong prediction of zero third party support empirically unpalatable, the observed levels of third-party support in constituencies are high enough to defy but the most lenient reading of Duvergerian equilibrium analysis. ${ }^{11}$ Furthermore, as the histograms in Table 1 reveal, successful strategic coordination in districts could have made a difference in determining the winner. In each year, the average share of the vote for the third place finisher in the constituency was enough so that, had it been jointly given to the candidate in second place, the winner would have been defeated. Apart from

\footnotetext{
${ }^{9} \mathrm{I}$ do not consider East German constituencies in 1990- the first election after reunification. In this election, the Liberal Democrats (FDP) - besides the CDU, the SPD and the PDS-enjoyed sizable levels of support among the East German electorate, thus effectively creating four-party competition at the constituency level. I also exclude West Berlin (as well as Berlin-Mitte) from the analysis, because it does not exhibit the same pattern of three-party competition as the rest of East Germany. Two districts, Leipzig I in 1994, and Fürstenwalde-Strausberg-Seelow in 1998, were excluded due to the SPD or the CDU's failure to run candidates in these elections. Another particular district that is excluded from the 2002 and 2005 analyses is Berlin-Friedrichshain-Kreuzberg-Prenzlauer Berg. While this district also features three-party competition, it is the Green party-not the CDU-which competes against the SPD and the PDS. Including the district would therefore require substituting Green party supporters for CDU supporters which makes interpretation of results somewhat awkward. Including the district in the analysis would, however, not change the results in any way.

${ }^{10}$ The somewhat remarkable strength of the PDS in East Germany is due to the fact that it inherited the ideology of the Socialist Unity Party of Germany (SED) of the former German Democratic Republic. Although the SED was abolished after reunification, support for its reformed predecessor, the PDS, remains strong among significant parts of the Eastern German population.

${ }^{11}$ It might appear from Table 1 that Duverger's law holds quite well for parties coming in fourth and fifth place. However, this result is not so much due to strategic voting as it owes to the scarcity of sincere support for those parties in the first place
} 
being a descriptively interesting phenomenon the absence of bipartisan outcomes thus also has some political relevance. This makes East Germany an appropriate setting for studying voter uncertainty.

\subsection{The importance of constituency elections in East Germany}

Before moving on to the empirical analysis, let me speak to a potential caveat against using East Germany as a test case. Given the compensational nature of the German election system, it might be argued that German voters should not immerse themselves in the difficulties of strategic voting. After all, successful candidates merely fill the seats allocated to their party according to its share of second votes, which might render constituency outcomes less important to German voters than, for instance, to voters in Great Britain where such outcomes directly affect the partisan composition of parliament.

Although some general arguments against this claim have been made elsewhere (see, e.g., Cox 1997; Herrmann and Pappi 2008), note that, in the context studied here, constituency elections actually do matter for parliamentary representation. On the one hand, they matter for PDS supporters (and opponents) because winning the constituency guarantees a seat in parliament even if the PDS's nationwide share of second votes falls short of the 5\% threshold of representation. Indeed, the threat of falling below the national threshold is binding for the PDS, as that party has failed to pass the hurdle for 1994 as well as 2002. In addition, small parties can circumvent the $5 \%$ threshold and have all their second votes counted anyway if they manage to win at least three seats in SMP contests. This provision helped the PDS in gaining proportional representation in parliament, despite its failure to meet the $5 \%$ vote threshold in 1994.

On the other hand, constituency elections also matter for supporters (and opponents) of the CDU and the SPD, because these elections generate so-called overhang seats (Überhangmandate). Overhang seats arise because electoral law guarantees a mandate to constituency candidates even if their party's state-wide share of second votes provided them with an insufficient number of parliamentary seats. In such an event, the seats of successful constituency candidates are simply added to the total seats in parliament. While overhang seats are often considered rare and accidental, their number increased markedly after reunification. ${ }^{12}$ Prior to reunification, the average number of overhang seats per election was 1.5 ; the postreunification average scores at about 11 (excluding the 2009 election with its 24 overhang seats). The East-West ratio of overhang seats (excluding 2009) in the post-reunification period is roughly 9:2, suggesting that the probability of an overhang seat occurring in East Germany is more than four times larger than in West Germany. ${ }^{13}$ The political impact of overhang seats became most visible in the 1994 election when sitting CDU chancellor Helmut Kohl was reelected by a margin of only two parliamentary votes (with two abstentions) after his party had managed to win 12 overhang seats (10 from East Germany) while the opposing SPD obtained only four overhang mandates (three from East Germany). Overall, between 1994 and 2005, one in seven candidates from East German constituencies was

\footnotetext{
${ }^{12}$ Comprehensive statistics on overhang seats can be found, for example, at: www.wahlrecht.de/ueberhang/ ueberhist.html (retrieved 03/03/2010).

${ }^{13}$ There are two obvious reasons for the prominence of overhang seats in the eastern part of Germany: lower turnout and less overall support for the SPD and the CDU. Lower turnout entails fewer second votes for parties and-because seats in parliament are filled in proportion to the number of second votes a party obtains in a given state-fewer seats are thus open for allocation to members from East German constituencies. The comparatively lower support for the SPD and the CDU in the East further amplifies this situation, increasing the likelihood of these parties winning more constituency seats by plurality than mandates according to PR.
} 
awarded an overhang seat. Note that this does not mean that only one in seven constituency races mattered for the partisan composition of parliament. The likelihood of an overhang seat depends on the number of second votes a party receives in a state relative to its national vote total (i.e., winning a constituency is more likely to yield an overhang seat the smaller the former is relative to the latter). Because overhang seats arise at the state level, every constituency race within a given state is important for creating overhang seats. Between 1994 and 2005, all eastern states save for Berlin yielded overhang seats in either two, three, or all four elections. Thus, overhang seats are not rare occurrences, at least in East Germany, nor can constituency elections be neglected for the distribution of power in parliament.

Given the electoral prospects of creating overhang seats for the CDU and the SPD or direct mandates for the PDS, the claim of voter indifference appears somewhat premature. In all of the elections considered here, constituency outcomes had an effect on the partisan composition of parliament. Thus, voters had no reason for being indifferent to the outcome of their local constituency race. Given its importance for determining overhang seats, in Sect. 5.3, I shall also address the question of whether strategic voting was decisive in determining the winner.

\subsection{Data and measures}

The data that is used are the vote counts of first and second votes, aggregated at the district level. To obtain a measure of strategic voting, previous studies are followed in assuming that the number of strategic votes a party receives or suffers from in a given district can be inferred from the difference in the number of first votes (which include potentially strategic votes) to second votes (which do not) (cf. Fisher 1973; Cox 1997; Bawn 1999; Gschwend et al. 2003). Thus, the dependent variable is each party's difference in first to second votes.

Party support is measured by the number of second votes a party receives in the constituency. If PR votes are cast sincerely, the relative frequencies (i.e., proportions) of second votes for the three main parties correspond to the parameters governing the distribution of party support in the constituency, $p_{j}$. According to the theoretical model, voters infer the values of these parameters by sampling second votes in the constituency (in reality, they might probe other voters' party preferences or distill the relevant information from secondary cues in their environment). If voters indeed sample from the distribution of second votes, their modal beliefs about party support will coincide with the true values $p_{j}$. I thus substitute the relative frequencies of second votes for voters' modal beliefs, $\pi$, when evaluating incentives for strategic voting in the district. ${ }^{14}$ Setting the mode this way does not imply that each voter knows the true values. It rather assumes, for the sake of analysis, that voter beliefs about the most likely distribution of party support are not systematically biased so that, even though voters may hold different beliefs individually, the average voter's modal belief will coincide with the true values. Importantly, however, if voters are uncertain, then their individual beliefs will vary widely, and consequently the precision around the average voter's belief will be small. The target of the subsequent estimation is therefore the precision of the average voter's belief, $s$. Only if $s$ is very large, the precision of voter beliefs is high and voters literally know the true values. If the available information is sparse (i.e., if voters are uncertain), however, then voters' modal beliefs will not be very informative, and hence $s$ will be small.

\footnotetext{
${ }^{14}$ Specifically, let $v_{j}$ denote the number of second votes received by one of the three major parties in the district then I calculate $\pi_{j}=v_{j} / \sum_{j=1}^{3} v_{j}$.
} 

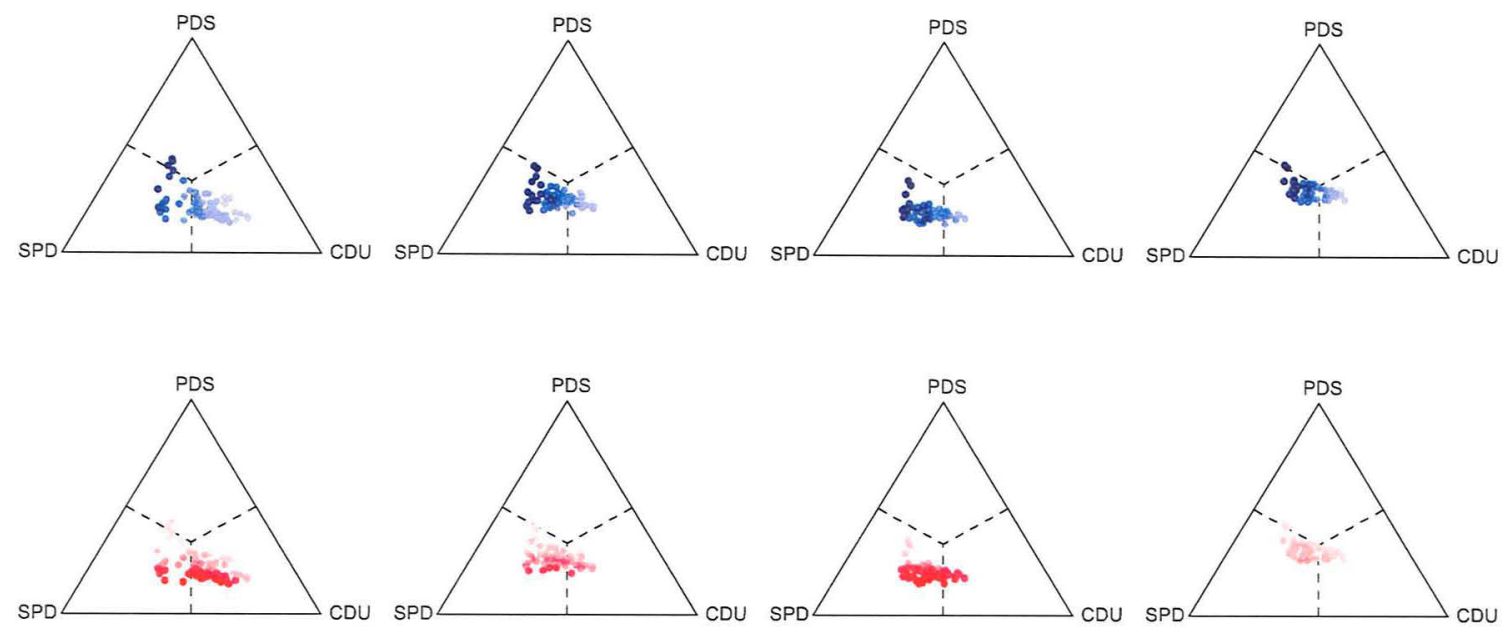

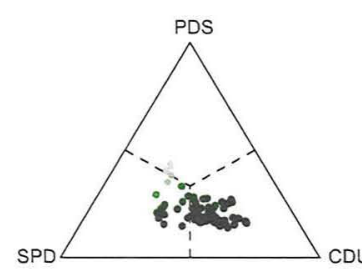

1994

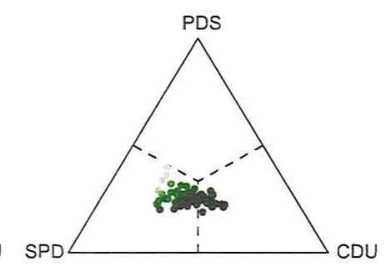

1998

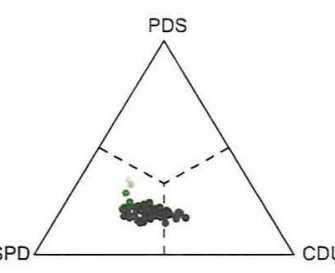

2002

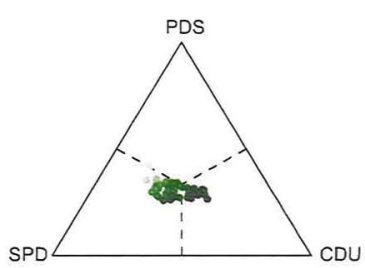

2005

Fig. 2 Party support and strength of strategic incentive for voters with different preference profiles in East German constituencies 1994-2005. Darker shading indicates stronger incentive to defect from first to second preference for voters with proficto shading indicates stronger in (middle row): $S \succ P$, green (bottom row) $C \succ P$ 
To get a sense of how the strategic incentive varies with the distribution of voter preferences, I computed the strategic incentive setting $s$ at some arbitrary value $(s=10)$. Figure 2 displays the configuration of party support along with the strategic incentive in each of the constituencies under study. ${ }^{15}$ As can be seen, in 1994 support for the CDU was strong but, since then shifted heavily toward the SPD. On the other hand, PDS support-facing a low in 2002 followed by a high in 2005-remains relatively stable, in the aggregate, throughout election periods. Most important for strategic voting is parties' expected order of finish, which appears as rather diverse within and across elections. For every election, there are constituencies in which the CDU is expected to come first, second, or third. The same holds true for the PDS and the SPD in 1994 and 2005. For 1998 and 2002, the PDS is expected to finish either second or third and the SPD is expected to win most of the time or, at least, to finish in second place. Hence, for every election year one can expect flows of strategic votes along each vertex of the triangle. That is, one can expect strategic votes from the CDU to the SPD by CDU supporters trying to avoid a PDS victory (and vice versa in 1994 and 2005). In the same manner, one can expect strategic votes going from the PDS to the CDU (and vice versa), and from the PDS to the SPD (and vice versa in 1994 and 2005).

As mentioned above, the German system with simultaneous PR-plurality voting provides a unique opportunity for studying the mechanics of strategic voting. However, a growing literature suggests that voters may also vote strategically under PR (see, e.g., Blais et al. 2006; Bargsted and Kedar 2009). In particular, German voters are often said to employ a socalled "threshold insurance strategy" or Leihstimme (Schoen 1999; Gschwend 2007). This means that supporters of the CDU or the SPD vote for their party's designated junior coalition partner to help it overcome the 5\% threshold of representation thereby guarding against the defeat of their preferred coalition. The possibility of such a strategic PR vote might undermine the value of second votes as a measure of voter preference. ${ }^{16} \mathrm{How}$ ever, to the extent that strategic PR voting occurs, note that it should aim at influencing the national election result, not the local constituency outcome. Because the situation in the district has no bearing on the decision to cast a strategic PR vote, we should not expect any systematic variation in strategic PR voting across constituencies. Thus, even in the presence of strategic PR voting, the variation in second votes across constituencies should still reflect differences in voter preferences. In addition, note that voters employing a threshold insurance strategy would only vote for their preferred party's designated coalition partner. Thus, strategic second votes would go only from the CDU to the FDP and from the SPD to the Green party, but not to the PDS (see Pappi and Thurner 2002; Shikano et al. 2009). One way to "correct" for the influence of strategic second votes would be to add back surplus second votes (i.e., potential strategic votes) for the Green party and the FDP to the second vote totals for the SPD and the CDU. Section 5.1 reports the results using this alternative measure of party support.

\section{Estimation strategy}

I now turn to a model for estimating voter information levels and strategic vote transfers between parties from observed voting records. The goal of the analysis is to estimate $s$ -

\footnotetext{
${ }^{15}$ For interpretation of simplex diagrams such as those in Fig. 2 with respect to vote shares, see, e.g., Upton (1994), Katz and King (1999), Grofman et al. (2004).

${ }^{16}$ While such strategic voting should work in favor of small parties, other studies suggest that strategic voting in PR elections might favor large parties (Cox and Shugart 1996; Bargsted and Kedar 2009; Abramson et al. 2010). For Germany, however, no such findings have been reported yet.
} 
the precision of voter beliefs. Formally, the value of $s$ corresponds to the number of voting intentions voters sample to inform their voting decision and evaluate parties' standings in the constituency race. Intuitively, it may be interpreted as the quality of information sources available to the voter.

From the strategic voting criterion in (2), recall that the number of strategic voters in a district should - all else being equal-increase with the strategic incentive. Assuming voters' intensities of preference (i.e., the log-utility ratios for first over second preference party) are randomly distributed across districts and parties, one can study strategic voting by examining voter responsiveness to the electoral situation as captured by the pivot likelihood ratios in the district. I therefore expect a party's difference in first to second votes across districts to move with the strategic incentive, i.e., to increase/decrease as the incentive grows/wanes. For instance, I expect the difference in first to second votes for the SPD to increase as the strategic incentive of a voter with preference $P \succ S$ grows. Also, an increase is expected in the difference of first to second votes for the SPD as the incentive of a voter with preference $C \succ S$ grows. Importantly, however, because strategic voters merely switch sides, the voting differentials for the deserted parties must decrease by the same number of votes as the differential for the receiving party increases. Thus if, say, for a unit change in the strategic incentive a thousand voters defect from the PDS to the SPD, the difference in first to second votes for the SPD must increase, and likewise the difference in first to second votes for the PDS must decrease by a thousand votes. The same holds with respect to other pairs of parties: for example, if the incentive to defect from the CDU to the SPD grows, the voting differentials of the SPD and the CDU should increase and decrease by the same number of votes.

To state this formally, the number of voters who switch sides in response to the strategic environment in their district must satisfy the following set of equations:

$$
\begin{aligned}
& S 1-S 2=\psi I_{C S}(s)+\psi I_{P S}(s)+0, \\
& C 1-C 2=-\psi I_{C S}(s)+0+\psi I_{P C}(s), \\
& P 1-P 2=0 \quad-\psi I_{P S}(s)-\psi I_{P C}(s),
\end{aligned}
$$

where $S 1-S 2, C 1-C 2$, and $P 1-P 2$ denote the difference in first to second votes for the SPD, the CDU and the PDS, respectively. Focusing on the strategic incentive variables first, note that a unit increase in the incentive to switch from one party to another is associated with an increase in $\psi$ votes for the receiving party and a decrease of the same amount for the deserted party. Note also that strategic switching involves only pairs of parties, so the vote differential of the third party is unaffected by strategic voting between the other two. Finally, note that the pivot likelihood ratio is symmetric with respect to parties ranking first and second in preference order, i.e., $I_{C S}=-I_{S C}, I_{P S}=-I_{S P}$ and $I_{P C}=-I_{C P} \cdot{ }^{17}$ Because

\footnotetext{
${ }^{17}$ For any pair of parties $i, j$ in a three-party system, the strategic incentive between them is symmetric, such that $I_{i j}=-I_{j i}$. To see this, note that

$$
I_{i j}=\log \frac{2 p_{i j}+p_{j k}}{2 p_{i j}+p_{i k}}=-\log \frac{2 p_{i j}+p_{i k}}{2 p_{i j}+p_{j k}} .
$$

Furthermore, note that the probability of being pivotal between parties $i$ and $j$ is the same as the probability of being pivotal between $j$ and $i$, i.e., $p_{i j}=p_{j i}$. Therefore,

$$
-I_{j i}=-\log \frac{2 p_{j i}+p_{i k}}{2 p_{j i}+p_{j k}}=-\log \frac{2 p_{i j}+p_{i k}}{2 p_{i j}+p_{j k}},
$$

which is the stated relation.
} 
the strategic incentive is symmetric for all pairs of parties, strategic voting in a district can effectively be summarized by three quantities, the incentive to switch between the CDU and the SPD, the incentive to switch between the PDS and the SPD, and the incentive to switch between the PDS and the CDU.

In line with strategic voting theory, parameters $s$ and $\psi$ are constrained to be equal across all types of voters, which means that supporters of certain parties are assumed to be neither systematically better informed nor to respond differently to strategic incentives than supporters of other parties. Theoretically, a voter's partisanship (i.e., the identity of her preferred party) has no bearing on her strategic behavior. The parameter $\psi$ simply works to scale the strategic incentive into observed votes. Estimating a common parameter for all voters implies that switches between all pairs of parties are, a priori, equally likely (as a robustness check, Sect. 5.1 reports on the results from estimating a modified version of the model, in which it is assumed that strategic voting between the PDS and the CDU does not occur). While voter uncertainty may, in principle, vary across constituencies, in the present analysis I restrict myself to estimating voters' overall average level of information.

To calibrate the model in (5), vote differentials are allowed to contain some noise, which is represented by independent random disturbance terms. The noise may result from unobserved variation in voters' relative preferences across districts and parties as well as idiosyncratic deviations from predicted behavior. Since voting differentials are affected not only by strategic voting, control variables are also included for district size and candidate popularity. District size, measured by the number of eligible voters in the constituency, may affect voting differentials as more populous districts can exhibit larger voting differentials than less populous ones. Candidate popularity may also lead to increases in first over second votes for a given party even in the absence of strategic voting. Incumbency status is included as a measure of candidate popularity since incumbent candidates have been demonstrated to enjoy a sizable advantage in various electoral settings (Cain et al. 1984; Gelman and King 1990; Levitt and Wolfram 1997; Bawn 1999; Reed 1999). To complete the model, a constant term is added for each party, allowing vote differentials to be nonzero in the presence of other nonmodeled factors. ${ }^{18}$ Taken together, this leads to the following statistical model:

$$
\begin{aligned}
& S 1-S 2=\alpha_{S}+\gamma V+\delta W_{S}+\psi I_{C S}(s)+\psi I_{P S}(s)+0+0+\epsilon_{S}, \\
& C 1-C 2=\alpha_{C}+\gamma V+\delta W_{C}-\psi I_{C S}(s)+0+\psi I_{P C}(s)+\epsilon_{C}, \\
& P 1-P 2=\alpha_{P}+\gamma V+\delta W_{P}+0-\psi I_{P S}(s)-\psi I_{P C}(s)+\epsilon_{P},
\end{aligned}
$$

where $\epsilon_{j}$ denotes a random error associated with each party's vote differential and $\alpha_{j}$ denotes a party specific constant. $V$ denotes the number of eligible voters in the constituency and $W_{j}$ is a dummy-variable scoring 1 if the incumbent is a member of party $j$ and 0 otherwise. In open seats and in districts that did not exist in the previous election, $W_{j}$ is set equal to 0 for all parties. ${ }^{19}$

\footnotetext{
${ }^{18}$ Apart from the reasons mentioned above, some voters may simply split their tickets to indicate a preference for a certain coalition (Roberts 1988; Pappi and Thurner 2002) or there might be other factors contingent to a certain party at a certain election. Besides, the total number of first votes cast in any given district generally is smaller than the number of second votes, suggesting that apart from splitting their tickets, some voters deliberately abstain from the first ballot (perhaps because their preferred party does not appear on the first ballot).

${ }^{19}$ Data on incumbency status were taken from Statistisches Bundesamt (various years). I thank Jens Hainmueller for sharing his data on incumbency for the 1994 and 1998 elections. Due to redistricting between 1998 and 2002, incumbency is excluded from model estimations for the 2002 election.
} 
To obtain estimates of $s, \psi, \gamma, \delta$, and $\alpha_{j}$ I fit (6) using maximum likelihood assuming that the random disturbances are drawn from a normal distribution with mean zero and variance $\sigma^{2}$. Equations (6) was also estimated without assuming a particular form for the error distribution via nonlinear least squares. Both methods yielded substantively the same results. On the technical side, however, the least squares approach often proved useful in facilitating the search for the maximum likelihood estimate in cases where the likelihood function exhibited local maxima. Using alternative starting values for $s$, covering a range from 1 up to 1000, confirmed that each estimation result constitutes a global maximum. To account for the postulated positive, negative, or zero relationships between vote differentials and strategic incentives, each incentive variable is multiplied by an indicator variable scoring either $1,-1$, or 0 , respectively. If there is strategic voting, then the sign on $\hat{\psi}$ must be positive.

Concerning significance testing, since both $s$ and $\psi$ are functionally dependent, I shall not pay attention to their individual significance. To see why, note that il $\psi$ is zero (i.e., no strategic voting), then $s$ is not identified (i.e., it could take on any value). Conversely, if $s$ is zero, then the strategic incentive is a constant and $\psi$ is unidentified. The critical question, therefore, is not whether we can reject the null hypothesis of any individual parameter being zero. Instead, we should ask whether both parameters together add some value to the explanation of vote differentials above the level that can be explained by simply modeling each party differential with a constant term. To address this question, likelihood-ratio tests are employed of the null hypothesis that the right-hand side of (5) (i.e., the strategic voting component) can be dropped from (6). In addition, since the likelihood-ratio approach does not penalize for introducing additional parameters, the contribution of $s$ and $\psi$ are evaluated on the basis of the Bayesian information criterion (BIC).

\section{Findings}

Table 2 summarizes the main results. Regarding voter uncertainty, recall that the parameter $s$ corresponds to the number of voting intentions voters sample from local information sources in order to inform their own voting decisions (i.e., to get a sense of parties' electoral support in the constituency). Small values suggest greater uncertainty, large values lesser uncertainty. In each election, the estimated strategic vote-flow parameter, $\hat{\psi}$, is positive-which suggests the presence of strategic voting - and voter uncertainty, $\hat{s}$, is roughly estimated as four in 1994, nine in 1998, five in 2002, and six in 2005. Likelihood-ratio tests and model comparisons on the basis of the BIC both strongly support the conclusion that the strategic voting model gives a better description of the relationships in the data than a model that does not assume strategic voting, except for the 2005 election, where the BIC-difference is small and estimates of $s$ and $\psi$ have much larger associated standard errors.

Interestingly, the estimates in Table 2 suggest that strategic voters operate under fairly high levels of uncertainty. This contrasts sharply with the standard assumption inherent in Duvergerian equilibrium analysis, which posits that the distribution of voter preferences in the constituency is known to the individual voter. Theoretically, this assumption corresponds to an infinitely large value of $s$. In practice, it would require at least an opinion poll of about 100 to 1000 people. The estimates of $s$ obtained here are several orders of magnitude below this hypothetical benchmark. Thus, contrary to the presumption underlying Duvergerian equilibrium analysis, these results corroborate the view of an average voter who is not blessed with opinion poll-quality data and, therefore, highly uncertain about the outcome of the constituency race. 
Table 2 Voter uncertainty and flows of strategic votes between parties

\begin{tabular}{|c|c|c|c|c|}
\hline & 1994 & 1998 & 2002 & 2005 \\
\hline Precision of voter beliefs $s$ & $\begin{array}{l}4.12 \\
(1.57)\end{array}$ & $\begin{array}{l}8.79 \\
(4.06)\end{array}$ & $\begin{array}{l}5.04 \\
(1.94)\end{array}$ & $\begin{array}{l}5.78 \\
(6.62)\end{array}$ \\
\hline Vote-flow parameter $\psi$ & $\begin{array}{l}5649 \\
(1751)\end{array}$ & $\begin{array}{l}5255 \\
(2156)\end{array}$ & $\begin{array}{l}8107 \\
(2792)\end{array}$ & $\begin{array}{l}4928 \\
(4625)\end{array}$ \\
\hline Incumbency $\delta$ & $\begin{array}{l}379 \\
(489)\end{array}$ & $\begin{array}{l}845 \\
(664)\end{array}$ & & $\begin{array}{l}2457 \\
(765)\end{array}$ \\
\hline Voting population $\times 10^{-4} \gamma$ & $\begin{array}{l}26 \\
(92)\end{array}$ & $\begin{array}{l}172 \\
(119)\end{array}$ & $\begin{array}{l}297 \\
(127)\end{array}$ & $\begin{array}{l}417 \\
(139)\end{array}$ \\
\hline SPD constant $\alpha_{S}$ & $\begin{array}{l}-361 \\
(1146)\end{array}$ & $\begin{array}{l}-915 \\
(1658)\end{array}$ & $\begin{array}{l}-8829 \\
(1994)\end{array}$ & $\begin{array}{l}-5990 \\
(2232)\end{array}$ \\
\hline CDU constant $\alpha_{C}$ & $\begin{array}{l}-454 \\
(1185)\end{array}$ & $\begin{array}{l}452 \\
(1689)\end{array}$ & $\begin{array}{l}-2836 \\
(1955)\end{array}$ & $\begin{array}{l}-1210 \\
(2236)\end{array}$ \\
\hline PDS constant $\alpha P$ & $\begin{array}{l}2578 \\
(1168)\end{array}$ & $\begin{array}{l}423 \\
(1674)\end{array}$ & $\begin{array}{l}3229 \\
(2024)\end{array}$ & $\begin{array}{l}-6290 \\
(2220)\end{array}$ \\
\hline $\log L$ & -1928.15 & -1974.91 & -1590.71 & -1584.27 \\
\hline $\log L_{\text {non-strategic }}$ & -1960.06 & -1994.34 & -1616.83 & -1591.41 \\
\hline $\mathrm{LR} \chi^{2}$ & $63.81^{*}$ & $38.85^{*}$ & $52.24^{*}$ & $14.28^{*}$ \\
\hline$\triangle \mathrm{BIC}$ & 53 & 28 & 42 & 4 \\
\hline $\mathrm{N}$ & 213 & 210 & 171 & 168 \\
\hline No. of constituencies & 71 & 70 & 57 & 56 \\
\hline
\end{tabular}

Entries are maximum likelihood estimates

Standard errors in parentheses

$\triangle \mathrm{BIC}$ denotes the difference in BIC between the strategic voting model, as shown, and a model without strategic voting (not shown); positive values indicate evidence in favor of strategic voting model

${ }^{*} \chi^{2}$-test $(\mathrm{df}=2)$ significant with $p<0.05$

Due to complete redistricting, the effect of incumbency could not be estimated for 2002

While differences in estimated uncertainty between elections are not large, a behavioral interpretation based on continuity in election outcomes might be consistent with the observed pattern: ${ }^{20}$ Accordingly, if voters' recent information (sampled from the constituency) about the likely election outcome fits their experience from the last election, this should reduce uncertainty. If recent information is at odds with past experience, however, then this suggests an change in voter preferences, and hence an increase in uncertainty. The low value of $s$ in 1994 could then result from the fact that this was the first election under the three-party system, which thereafter became characteristic of East Germany. The ensuing reduction in uncertainty in 1998 might be the product of this rough overall stability in voter preferences, coupled with greater clarity about the PDS being the third placed party in many constituencies. General redistricting between 1998 and 2002 increased uncertainty again although the general three-party pattern with PDS mostly in third place prevailed. The 2005 election then witnessed a large shift in voter preferences, in particular, the two large parties, the CDU and the SPD, suffered from severe losses in terms of second votes, while the PDS

\footnotetext{
${ }^{20}$ See Reed (1990) for a similar behavioral interpretation.
} 
substantially increased its share of voters, largely at the expense of the SPD (which can also be seen from Fig. 2).

Consistent with findings of previous studies of strategic voting in Germany (Cox 1997; Bawn 1999; Gschwend et al. 2003), the results also suggest the presence of strategic voting, which can be seen from the positive estimates of the vote-flow parameter $\psi$. Each estimate gives the average number of voters who defect to second preference for a unit increase (or decrease) in the strategic incentive. Due to different scaling of the strategic incentive, as determined by $\hat{s}$, the numbers are not comparable between elections. Computing the strategic incentive on the basis of $\hat{s}$ for a voter with preference $P \succ S$, for example, yields ranges of about -0.11 to 0.41 in $1994,0.01$ to 0.53 in $1998,0.06$ to 0.48 in 2002 , and -0.08 to 0.19 in 2005 . Thus, an increase from zero to the maximum value of the strategic incentive for this type of voter corresponds roughly to $2,316(5649 \times 0.41)$ predicted strategic votes in 1994, and likewise 2,785 votes in 1998, 3,891 votes in 2002, and 936 votes in 2005 .

Concerning the control variables, the small (and insignificant) effects of incumbency on voting differentials in 1994 and 1998, at first sight, appear to be at odds with the general literature on incumbency advantage. It should be mentioned that incumbency does exhibit significant effects in the baseline model without the strategic voting component (not shown in Table 2). However, the effect largely disappears once strategic voting is controlled for. Among the few studies dealing with incumbency advantage in Germany (Bawn 1999; Moser and Scheiner 2005; Hainmueller and Kern 2008) only Moser and Scheiner (2005) and Bawn (1999) control for the possibility of strategic voting. However, in contrast to the present study, those earlier contributions employ a much less sophisticated model of strategic voting that does not consider vote transfers and that accounts only for the closeness of the election instead of the full strategic incentive. Furthermore, in their comparative study on ticket-splitting in several mixed electoral systems, Moser and Scheiner find that Germany displays the weakest incumbency effects of all countries considered. They attribute this apparent lack of personal vote seeking to the dominance of parties in German politics and the disincentives to party leadership of encouraging personal vote seeking for maintaining party discipline. In a recent study on the incumbency advantage in German constituency elections, Hainmueller and Kern (2008) find that incumbent status not only helps the candidate but also the candidate's party. Employing a regression discontinuity design, the authors show that the vote advantage of the incumbent is virtually the same in both ballots, suggesting that popular incumbents also attract additional PR votes for their parties. If this is true, we would not expect incumbency to have a significant effect on voting differentials to begin with. ${ }^{21}$ Thus, while incumbency does not come out as a strong predictor of vote differentials in the present analysis, we should be cautious in interpreting this as evidence against incumbency advantage in Germany.

\subsection{Sensitivity analyses}

How sensitive are those results to deviations from sincere voting on the PR ballot? Section 3.2 suggests a way to correct for potentially strategic PR voting by adding back surplus list votes of the FDP and the Green party to the vote totals of their respective senior coalition partners: the CDU and the SPD. That is, all second votes obtained by the Green party beyond

\footnotetext{
${ }^{21}$ In addition, if the vote advantage of the incumbent indeed spills over into the PR ballot, as the results of Hainmueller and Kern (2008) suggest, then support levels in the constituency as measured by the proportions of second votes would actually reflect the incumbent's advantage in the district, and thus provide an even better representation of voter preferences with respect to the plurality contest.
} 
Table 3 Sensitivity analysis: correcting for potentially strategic PR votes

\begin{tabular}{|c|c|c|c|c|}
\hline & 1994 & 1998 & 2002 & 2005 \\
\hline Precision of voter beliefs $s$ & $\begin{array}{l}5.06 \\
(1.91)\end{array}$ & $\begin{array}{l}9.69 \\
(4.40)\end{array}$ & $\begin{array}{l}7.38 \\
(3.13)\end{array}$ & $\begin{array}{l}14.61 \\
(15.73)\end{array}$ \\
\hline Vote-flow parameter $\psi$ & $\begin{array}{l}4908 \\
(1548)\end{array}$ & $\begin{array}{l}5185 \\
(2147)\end{array}$ & $\begin{array}{l}5832 \\
(2356)\end{array}$ & $\begin{array}{l}1731 \\
(1664)\end{array}$ \\
\hline Incumbency $\delta$ & $\begin{array}{l}582 \\
(507)\end{array}$ & $\begin{array}{l}592 \\
(710)\end{array}$ & & $\begin{array}{l}2720 \\
(694)\end{array}$ \\
\hline Voting population $\times 10^{-4} \gamma$ & $\begin{array}{l}-80 \\
(95)\end{array}$ & $\begin{array}{l}53 \\
(126)\end{array}$ & $\begin{array}{l}131 \\
(130)\end{array}$ & $\begin{array}{l}79 \\
(135)\end{array}$ \\
\hline SPD constant $\alpha_{S}$ & $\begin{array}{l}922 \\
(1186)\end{array}$ & $\begin{array}{l}-232 \\
(1765)\end{array}$ & $\begin{array}{l}-7644 \\
(2044)\end{array}$ & $\begin{array}{l}-2561 \\
(2161)\end{array}$ \\
\hline CDU constant $\alpha_{C}$ & $\begin{array}{l}170 \\
(1226)\end{array}$ & $\begin{array}{l}1276 \\
(1794)\end{array}$ & $\begin{array}{l}-1119 \\
(1999)\end{array}$ & $\begin{array}{l}-866 \\
(2152)\end{array}$ \\
\hline PDS constant $\alpha_{P}$ & $\begin{array}{l}3912 \\
(1209)\end{array}$ & $\begin{array}{l}2314 \\
(1788)\end{array}$ & $\begin{array}{l}5790 \\
(2074)\end{array}$ & $\begin{array}{l}-960 \\
(2149)\end{array}$ \\
\hline $\log L$ & -1935.37 & -1987.83 & -1594.32 & -1578.91 \\
\hline $\log L_{\text {non-strategic }}$ & -1965.91 & -2006.63 & -1619.24 & -1582.59 \\
\hline $\mathrm{LR} \chi^{2}$ & $61.07^{*}$ & $37.60^{*}$ & $49.85^{*}$ & $7.36^{*}$ \\
\hline$\triangle \mathrm{BIC}$ & 50 & 27 & 40 & -3 \\
\hline $\mathrm{N}$ & 213 & 210 & 171 & 168 \\
\hline No. of constituencies & 71 & 70 & 57 & 56 \\
\hline
\end{tabular}

Entries are maximum likelihood estimates

Standard errors in parentheses

$\triangle \mathrm{BIC}$ denotes the difference in BIC between the strategic voting model, as shown, and a model without strategic voting (not shown); positive values indicate evidence in favor of strategic voting model

${ }^{*} \chi^{2}$-test $(\mathrm{df}=2)$ significant with $p<0.05$

Due to complete redistricting, the effect of incumbency could not be estimated for 2002

its number of first votes in the district could be taken as strategic votes from otherwise sincere SPD voters and counted as sincere SPD votes. Likewise, all second votes for the FDP beyond that party's number of first votes could be counted as sincere CDU votes. Although somewhat crude, this method should provide us with some indication of how sensitive the results are to deviations from sincere PR voting.

Table 3 reports the estimation results under this alternative counting scheme. As can be seen, no substantial changes occur. Only the 2005 estimate of voter information levels increases considerably, but the model now fits the data even worse than the nonstrategic baseline model, as can be seen from the negative BIC difference. Note that the coding scheme assumes a most extreme scenario where all surplus second votes for the FDP and the Green party come from CDU and SPD supporters, which empirically does not need to be the case (some FDP and Green party voters might simply abstain from the constituency ballot). Thus, the findings in Table 3 suggest that strategic PR voting has little bearing on our estimates of voter uncertainty.

Other robustness checks have been conducted; one employing second vote shares from the previous election as measures of voter expectations about party support, again taking into account potentially strategic second votes or not. The idea behind this approach is that 
voters may use (their memory of) past results as a baseline for the current election. The parameter $s$ would then indicate the average voter's certainty that things will stay the same. The results of this estimation led to substantively the same conclusions as those reported in Tables 2 and 3. Another robustness check concerned the assumption of equal vote-flows between all pairs of parties. Setting $\psi_{P C}(s)=0$ in (6), a modified version of the model was estimated that did not allow for strategic switching between the CDU and the PDS-the parties that are often perceived as being located in far ends of the political spectrum. Again, estimates of uncertainty were substantively similar. However, excluding the possibility of strategic voters switching between the PDS and the CDU resulted in a poorer model fit, i.e., higher values of BIC and smaller log-likelihoods than the model considered in (6). Note that this is not a trivial conclusion, since the two-way switching model is not nested in the three-way switching model, i.e., one cannot be obtained as a special case of the other in the estimation process. Finally, adding control variables for urbanization (i.e., major cities) and the share of FDP and Green party supporters in the constituency did not make any difference. Detailed results of all additional analyses are available from the author.

\subsection{Predicting strategic voter movements}

Where did strategic votes go? Which parties benefited most from strategic voting? Based on the results from Table 2, Fig. 3 shows the predicted strategic vote transfers between parties at the district level. There are two (equivalent) ways to read these graphs: one focusing on parties and how they were affected by strategic voting, the other focusing on voters of certain types and which parties they voted for. From the party perspective, for instance, all dots lying above zero in the first two graphs for each year correspond to votes won by SPD and those falling below zero correspond to votes lost by the SPD. Likewise, all dots below zero in the last two graphs for each year correspond to votes won by the PDS, while positive values correspond to losses by the PDS. Votes for the CDU are given by positive values in the last graph (negative values for losses) and negative values in the first graph of each year (positive values for losses). From the voter perspective, negative values in the first two graphs for each election year correspond to SPD supporters and their decisions to vote for either the CDU or the PDS; positive values in the last two graphs for each year represent the decisions of PDS voters to vote for one of the other two parties; and positive values in the first graph give the decisions of CDU supporters to vote for the SPD and negative values in the last graph give the decisions of CDU supporters to switch to the PDS.

Inspecting Fig. 3, some regularities are apparent: the PDS seems to suffer most from strategic voting, while the SPD and the CDU seem to be the main beneficiaries. This mirrors the competitive situation in constituencies presented earlier (see Fig. 2), where the CDU and the SPD were often expected to come either in first or second and the PDS in third. Nevertheless, the model predicts also shifts toward the PDS. Although these shifts occur only in few constituencies, they can nevertheless be of substantial size. Again, this coincides with the earlier observation that, for every election, some districts saw either the CDU or the SPD in third position. Finally, there is a mixed pattern of strategic exchange between the SPD and the CDU. In 1994 and 2005, strategic voting shifted more often towards the CDU, whereas in 1998 and 2002 the SPD received more often strategic votes from CDU supporters. However, in all elections, strategic exchange between the SPD and the CDU appears smaller overall than transfers between either party and the PDS, which is due to the comparatively lower incentive SPD and CDU supporters face for deserting their first preference. 
1994

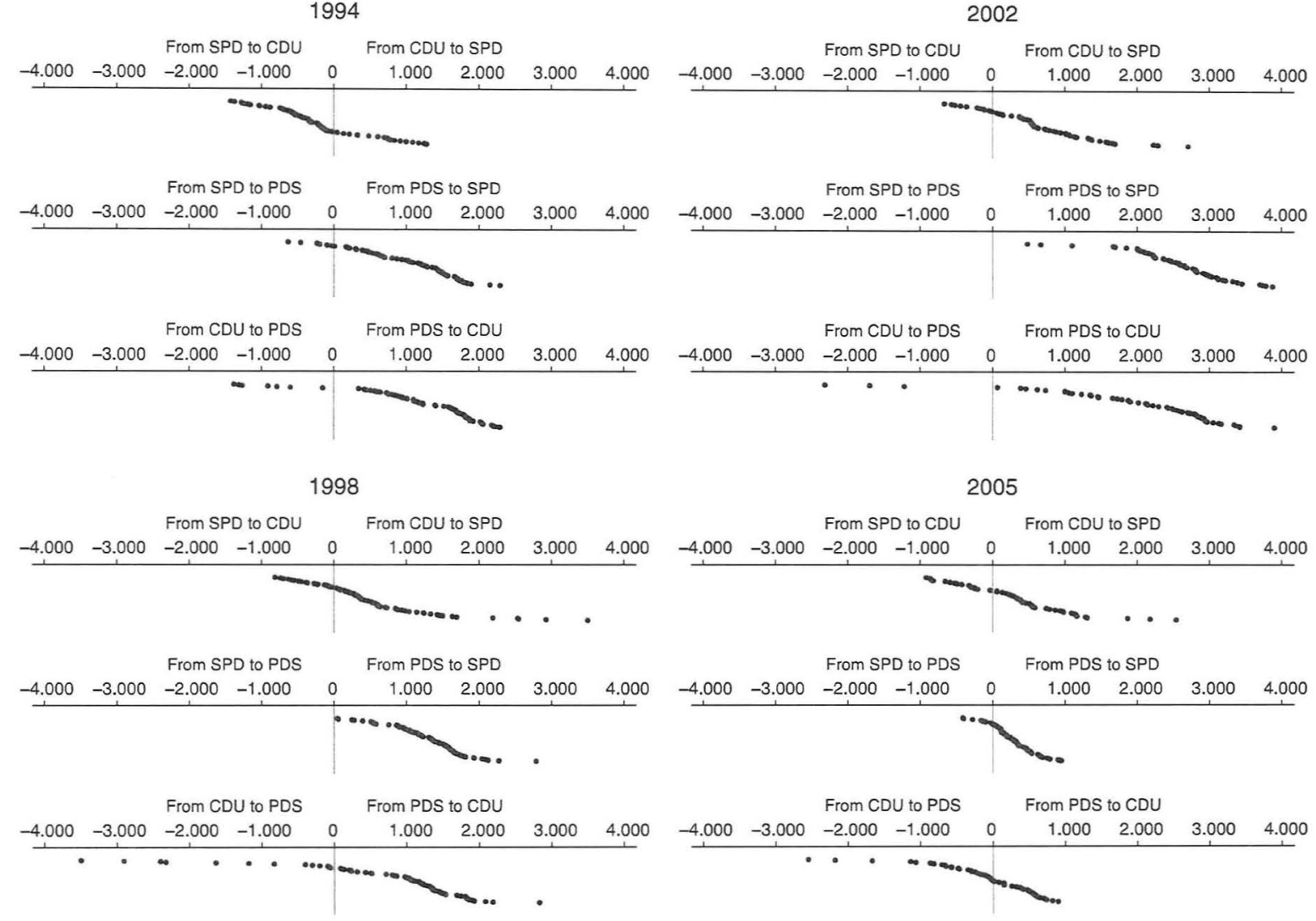

Fig. 3 Predicted strategic shifts 1994-2005. Each dot represents the predicted number of voters, $\hat{\psi} I_{i j}(\hat{s})$, who defect from their first to second preference party in a given district. In each subgraph districts are ordered (top to bottom) by magnitude of predicted strategic shift 


\subsection{The relevance of strategic voting}

Given these predictions, what is the overall scope of strategic voting? The question pertains, on the one hand, to the prominence of strategic voting, but also to the impact of strategic voting on electoral outcomes. Computing the ratio of total strategic to total valid votes for each year, it is estimated that $2.7 \%$ in $1994,2.4 \%$ in $1998,3.7 \%$ in 2002 and $0.9 \%$ of first votes cast in 2005 were strategic. Overall, strategic voting is clearly not a large scale phenomenon. Each year, only a small fraction of votes shift in response to the electoral situation. High levels of uncertainty obviously prevents excessive desertion of third place parties.

Although the overall number of strategic votes is relatively small, in simple plurality elections, it often needs no more than a few votes to tip the scales in the constituency. To assess the relevance of strategic voting, it is thus desirable to produce district-level estimates of strategic voting. Such estimates are rarely reported in studies of strategic voting. As we have already seen in the previous section with respect to voter movements, the present model allows for district-level predictions.

The prominence of strategic voting for individual districts is displayed in Figs. 4 and 5. Redistricting between 1998 and 2002 prohibits comparisons of districts across all four election cycles, but it can be seen that the share of strategic voters differs across districts as well as between elections, ranging from almost nothing up to $6 \%$. To facilitate comparison, districts showing a significant difference between both years are visually distinguished from those that do not. ${ }^{22}$ Between 1994 and 1998, the share of strategic voters within districts remained quite stable. Only a handful of districts show sizable changes in the number of strategic voters; for example, increases in constituencies in Berlin, Potsdam, and Rostock and decreases in Chemnitz, Weimar, and Zwickau. Greater differences emerge between 2002 and 2005. Here, only a few districts show similar levels of strategic voting in both years like, for example, districts in Berlin, Frankfurt (Oder) or Potsdam. For all other districts, predicted levels of strategic voting in 2005 are lower than in 2002.

Given the variability of strategic voting across districts, it appears reasonable to expect strategic voting to have an impact on constituency outcomes. In a last step, I assess the potential that strategic voting might have overturned constituency elections. Table 4 gives a list of all constituencies in which the predicted strategic shift for any party exceeds the margin of victory, i.e., the difference in first votes between winner and runner-up. For three of the four election years, I find such closely contested constituencies. Thus, there is indication that strategic voting can make a difference on the district level. One could go further and recalculate the margin of victory, absent predicted strategic voting (not shown). The results of these exercises suggest that strategic voting did not go so far as to overturn the outcome in a particular constituency contest. In other words, the net advantages of the winner due to strategic voting did not exceed the margin of victory.

\section{Conclusion}

Strategic voting and electoral coordination on bipartisan outcomes requires that voters are well informed about the electoral situation in the constituency. In this paper, I empirically assessed the impact of uncertainty on strategic voting. Calibrating a decision-theoretic model

\footnotetext{
22 Significance was determined if, in a given district, the simulated share of strategic voters for one year was larger than for the other year at least $95 \%$ of the time. Simulation of predicted values was performed by taking bootstrap samples from the sampling distribution of the model's parameters (King et al. 2000).
} 


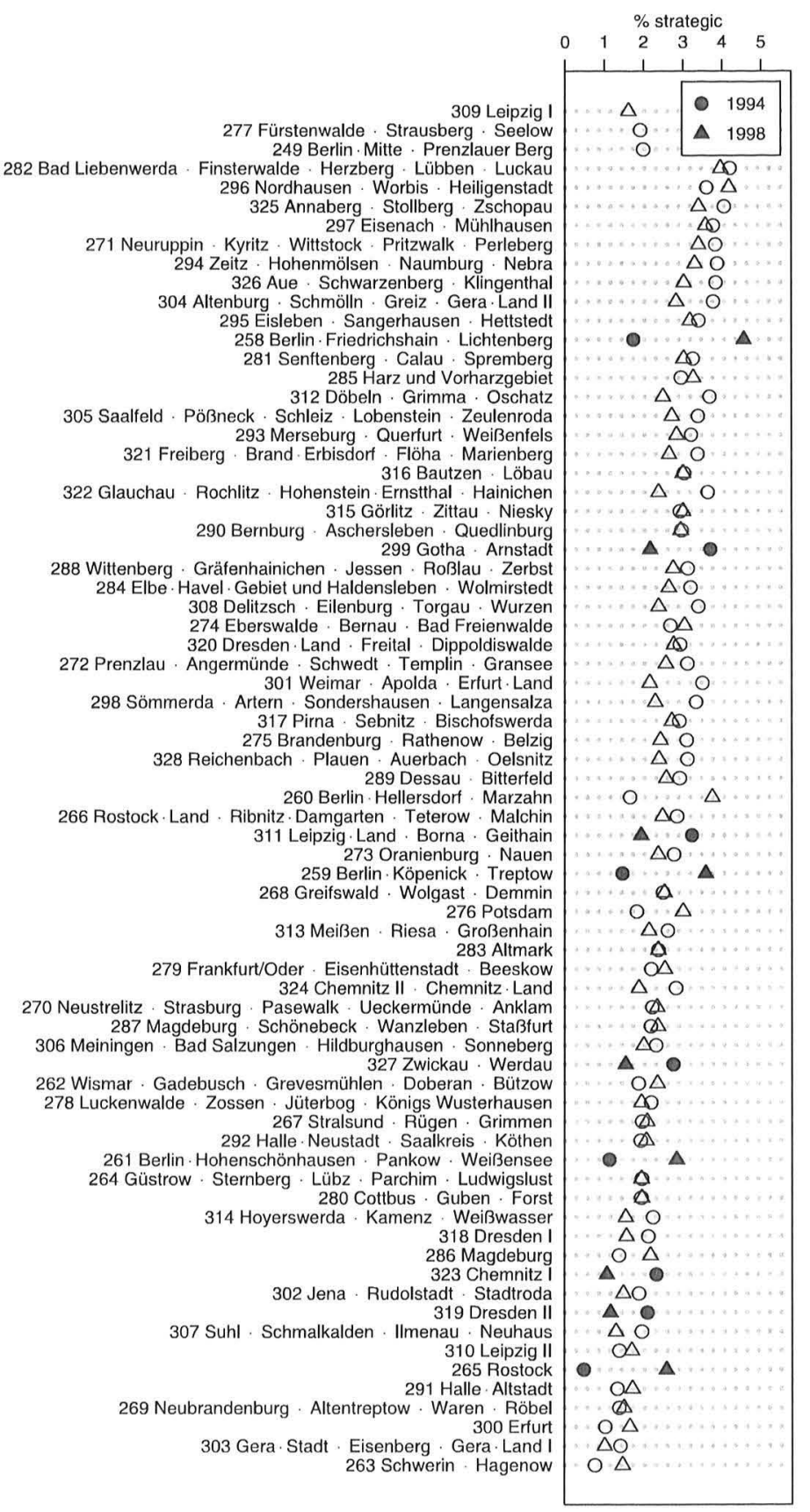

Fig. 4 Share of strategic votes in all valid votes cast in each district in 1994 and 1998. Strategic votes predicted from results in Table 2. Districts are displayed in descending order by the sum of strategic votes cast in both years. For the top three districts in the graph, suitable data was only available for one year (see footnote 9). Average frequency of strategic votes is $2.7 \%$ in 1994 and $2.4 \%$ in 1998. Filled markers indicate significant difference in strategic voting between two elections $(p<0.05)$, as determined from parametric bootstrap simulations (see footnote 22) 


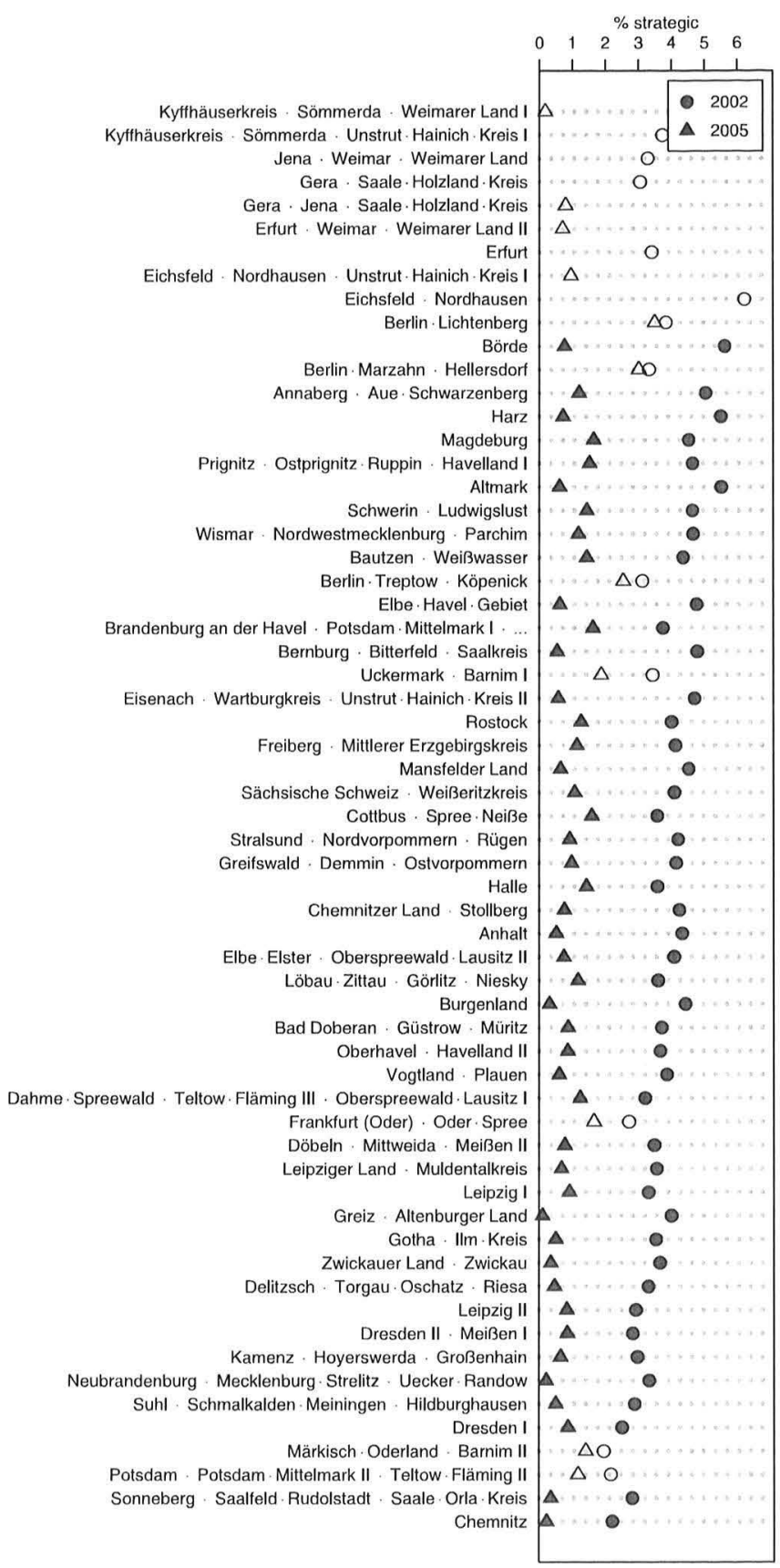

Fig. 5 Share of strategic votes in all valid votes cast in each district in 2002 and 2005. Strategic votes predicted from results in Table 2. Districts are displayed in descending order by the sum of strategic votes cast in both years. The top nine districts could not be matched due to redistricting between elections. Average frequency of strategic votes is $3.7 \%$ in 2002 and $0.9 \%$ in 2005. Filled markers indicate significant difference in strategic voting between two elections $(p<0.05)$, as determined from parametric bootstrap simulations (see footnote 22) 
Table 4 Did strategic voting decide constituency elections? Predictions from strategic vote-flow model ${ }^{1}$

\begin{tabular}{|c|c|c|c|c|c|c|c|c|}
\hline & State & Constituency & Winner & Runner-Up & $\begin{array}{l}\text { Margin of } \\
\text { Victory }\end{array}$ & $\begin{array}{l}\text { Predicted } \\
C \rightarrow S\end{array}$ & $\begin{array}{l}\text { Strategic } \\
P \rightarrow S\end{array}$ & $\begin{array}{l}\text { Shift }^{2} \\
P \rightarrow C\end{array}$ \\
\hline \multirow[t]{4}{*}{1994} & Meckl.-W. Pom. ${ }^{3}$ & 262 Wismar/Gadebusch/... & CDU & SPD & 793 & -76 & 1025 & 1096 \\
\hline & Brandenburg & 281 Senftenberg/Calau/Spremberg & SPD & CDU & 1461 & 40 & 1687 & 1654 \\
\hline & Saxony-Anhalt & 283 Altmark & SPD & CDU & 988 & -30 & 1490 & 1516 \\
\hline & Saxony-Anhalt & 291 Halle-Altstadt & SPD & $\mathrm{CDU}$ & 192 & -148 & 584 & 728 \\
\hline \multirow[t]{3}{*}{1998} & Meckl.-W. Pom. & 266 Rostock-Land/Ribnitz-Damgarten/... & SPD & $\mathrm{CDU}$ & 408 & 88 & 1306 & 1229 \\
\hline & Meckl.-W. Pom. & 270 Neustrelitz/Strasburg/... & SPD & $\mathrm{CDU}$ & 13 & -56 & 1222 & 1272 \\
\hline & Saxony & 322 Glauchau/Rochlitz/... & SPD & $\mathrm{CDU}$ & 1264 & 43 & 1722 & 1688 \\
\hline \multirow[t]{3}{*}{2002} & Meckl.-W. Pom. & 16 Greifswald/Demmin/Ostvorpommern & CDU & SPD & 1136 & -109 & 2796 & 2878 \\
\hline & Saxony-Anhalt & 74 Burgenland & SPD & $\mathrm{CDU}$ & 1464 & 410 & 3224 & 2933 \\
\hline & Saxony & 168 Vogtland/Plauen & $\mathrm{CDU}$ & SPD & 1344 & 93 & 3116 & 3050 \\
\hline
\end{tabular}

${ }^{1}$ Listed are constituencies where the predicted strategic shift for any party exceeds the margin of victory

${ }^{2}$ Arrows indicate direction of strategic shift, negative values imply shift in opposite direction

${ }^{3}$ Mecklenburg-Western Pomerania 
of strategic voting to electoral data from three-party simple plurality elections in East Germany, I found evidence for high levels of uncertainty in voter beliefs about the underlying electoral situation. While voters do vote strategically, their responsiveness to electoral incentives appears to be dampened by uncertainty about electoral outcomes. The level of uncertainty revealed in the analysis is hardly compatible with the assumption underlying models of Duvergerian equilibrium. It is, however, in accordance with recent studies of voting equilibria involving incomplete strategic voting.

Unlike other studies of strategic voting, particularly those based on national survey data (e.g., Cain 1978; Niemi et al. 1992; Blais and Nadeau 1996; Alvarez and Nagler 2000), the present study also yielded predictions about levels of strategic voting and vote transfers within individual constituencies. Accordingly, strategic voting within districts ranged up to $6 \%$ of the total votes cast. The SPD and the CDU were found to be the main beneficiaries of strategic voting in most districts, largely at the expense of the PDS. Strategic votes by SPD supporters almost always went to the CDU and only rarely to the PDS, while CDU supporters voted strategically for either the SPD or the PDS. Although strategic voting was found to be of small scale-roughly $2.4 \%$ overall-there are nevertheless a couple of close contests in which the number of strategic votes for any party exceeded that party's margin of victory.

Strictly speaking, due to the focus on one specific context (constituency elections in East Germany), one cannot infer from these results the presence of strategic uncertainty in plurality elections elsewhere. For instance, whether or not uncertainty also conditions tactical voting in British elections remains yet to be shown. Nevertheless, the present findings can be interpreted as first evidence for the possibility that the absence of strictly Duvergerian outcomes may be caused by insufficient levels of voter information about the competitive situation in local constituencies. While the focus of the study was on a context with three parties, we would expect the problem to be even more severe in multiparty elections. Because the fraction of votes needed to win decreases with the number of parties, in a situation with many parties even a small change in voter support might be enough for a party to excel from fourth or fifth into first place. Thus, the more parties compete for a single seat, the more uncertain voters should become about the outcome.

From a theoretical standpoint, one might argue, the analysis is limited insofar as it treats strategic voting as a decision-theoretic problem. Voters respond only to their beliefs and do not anticipate strategic voting by others. This somewhat naive conception of a voter would, in principle, prohibit any direct inference about coordinated outcomes such as Duvergerian equilibria. However, note that even in the decision-theoretic setting employed here, more accurate beliefs should lead to more strategic voting and, as a result, more bipartisan outcomes. Furthermore, if there is indication of uncertainty in the simpler decision-theoretic context such uncertainty should carry over to a game-theoretic setting as well. Thus, even without initially assuming a game-theoretic setup, the analysis still provides insight into the link between voter uncertainty and the likelihood of Duvergerian outcomes.

While the present study inferred uncertainty only indirectly from observed voting records, the results obtained in the analysis call for more research on this important variable. Future research might concentrate on examining the effect of voter information more directly, examining how the quality of information from different sources (e.g., media versus friends) affects the propensity to vote strategically. Also, we need to know more about which contextual factors drive voter information levels. For example, does constituency campaigning or the amount of election coverage in the media affect voter uncertainty? And to what extent do national polls and other nonlocal electoral information influence voters' judgments about local outcomes? Finally, looking at voter networks might yield further insights into 
voter belief formation. If, for example, in low-information environments, electoral information is spread mainly by word-of-mouth, then the composition of personal networks should be highly influential in determining strategic voting. In particular, social networks might introduce systematic biases in voter expectation formation as people with similar preferences tend to stick together. In effect, this would lead voters to overestimate the chances of their preferred candidate and make them less likely to vote strategically. In order to tease out these contextual differences, we need to develop better measures for voter information levels. In addition, individual-level tests of these relationships require more extensive survey data than presently available.

For the moment, we are left with the indication that uncertainty plays a key role in determining voter behavior in real-world elections. At least at the constituency level, elections exhibit high levels of uncertainty which, in turn, limit the extent to which voters react dynamically to electoral incentives. An important implication of this finding is that increasing the amount of information available to voters about the constituency race, for example, by means of constituency-wide polls or extensive local media coverage should lead to more accurate expectations, more strategic voting, and hence more bipartisan outcomes. In practical terms, politicians expecting to come in second place should invest in increasing voter information levels (for instance by publicizing results of constituency polls), as this is likely to generate strategic votes from supporters of the trailing candidate. Apparently, many realworld plurality elections still keep large untapped potentials for voter coordination.

Acknowledgements I thank Thomas Bräuninger, Reiner Eichenberger, Thomas Gschwend, Indridi H. Indridason, Franz Urban Pappi, Susumu Shikano, Frank Steffen, as well as the editor and three anonymous referees for valuable comments and advice. A previous version of this paper, titled "Estimating Uncertainty in Strategic Voting," has been awarded the Wicksell Prize at the Annual Meeting of the European Public Choice Society, Jena, March 2008.

\section{References}

Abramson, P. R., Aldrich, J. H., Blais, A., Diamond, M., Diskin, A., Indridason, I. H., Lee, D. J., \& Levine, R. (2010). Comparing strategic voting under FPTP and PR. Comparative Political Studies, 43, 61-90.

Alvarez, M. R., \& Nagler, J. (2000). A new approach for modelling strategic voting in multiparty elections. British Journal of Political Science, 30, 57-75.

Alvarez, M. R., Boehmke, F. J., \& Nagler, J. (2006). Strategic voting in British elections. Electoral Studies, $25,1-19$.

Austen-Smith, D. (2000). Redistributing income under proportional representation. Journal of Political Economy, 108, 1235-1269.

Bargsted, M., \& Kedar, O. (2009). Coalition-targeted Duvergerian voting: how expectations affect voter choice under proportional representation. American Journal of Political Science, 53(2), 307-323.

Bawn, K. (1999). Voter responses to electoral complexity: ticket splitting, rational voters and representation in the federal republic of Germany. British Journal of Political Science, 29, 487-505.

Black, J. H. (1978). The multicandidate calculus of voting: application to Canadian federal elections. American Journal of Political Science, 22, 609-638.

Blais, A., \& Nadeau, R. (1996). Measuring strategic voting: a two-step procedure. Electoral Studies, 15, 39-52.

Blais, A., Young, R., \& Turcotte, M. (2005). Direct or indirect? assessing two approaches to the measurement of strategic voting. Electoral Studies, 24, 163-176.

Blais, A., Aldrich, J. H., Indridason, I. H., \& Levine, R. (2006). Do voters vote for government coalitions? Testing Downs' pessimistic conclusion. Party Politics, 12, 691-705.

Cain, B. E. (1978). Strategic voting in Britain. American Journal of Political Science, 22, 639-655.

Cain, B. E., Ferejohn, J. A., \& Fiorina, M. P. (1984). The constituency service basis of the personal vote for U.S. representatives and British members of parliament. American Political Science Review, 78, $110-125$. 
Chhibber, P., \& Kollman, K. (1998). Party aggregation and the number of parties in India and the United States. American Political Science Review, 92(2), 329-42.

Cox, G. W. (1994). Strategic voting under the single nontransferable vote. American Political Science Review, $88,608-621$.

Cox, G. W. (1997). Making votes count: strategic coordination in the world's electoral systems. Cambridge: Cambridge University Press.

Cox, K. E., \& Schoppa, L. J. (2002). Interaction effects in mixed-member electoral systems: theory and evidence from Germany, Japan, and Italy. Comparative Political Studies, 35(9), 1027-1053.

Cox, G., \& Shugart, M. S. (1996). Strategic voting under proportional representation. Journal of Law, Economics and Organization, 12, 299-324.

Diwakar, R. (2007). Duverger's law and the size of the Indian party system. Party Politics, 13, 539-561.

Felsenthal, D. S., Rapoport, A., \& Maoz, Z. (1988). Tacit cooperation in three-alternative non-cooperative voting games: a new model of sophisticated behaviour under the plurality procedure. Electoral Studies, 7, 143-161.

Fey, M. (1997). Stability and coordination in Duverger's law: a formal model of preelection polls and strategic voting. American Political Science Review, 91, 135-147.

Fisher, S. L. (1973). The wasted vote thesis: West German evidence. Comparative Politics, 5, 293-299.

Fisher, S. D. (2004). Definition and measurement of tactical voting: the role of rational choice. British Journal of Political Science, 34, 125-166.

Forsythe, R., Myerson, R. B., Rietz, T. A., \& Weber, R. J. (1993). An experiment on coordination in multicandidate elections: the importance of polls and election histories. Social Choice and Welfare, 10, 223247.

Forsythe, R., Rietz, T. A., Myerson, R. B., \& Weber, R. J. (1996). An experimental study of voting rules and polls in three-candidate elections. International Journal of Game Theory, 25, 355-383.

Gaines, B. J. (1999). Duverger's law and the meaning of Canadian exceptionalism. Comparative Political Studies, 32, 835-861.

Galbraith, J. W., \& Rae, N. C. (1989). A test of the importance of tactical voting. British Journal of Political Science, 19, 126-136.

Gelman, A., \& King, G. (1990). Estimating incumbency advantage without bias. American Journal of Political Science, 34(4), 1142-1164.

Grofman, B., Chiaramonte, A., D’Alimonte, R., \& Feld, S. L. (2004). Comparing and contrasting the uses of two graphical tools for displaying patterns of multiparty competition. Party Politics, 10, 273-299.

Grofman, B., Blais, A., \& Bowler, S. (Eds.) (2009). Studies in public choice: Vol. 13. Duverger's law of plurality voting. The logic of party competition in Canada, India, the United Kingdom and the United States. Berlin: Springer.

Gschwend, T. (2007). Ticket-splitting and strategic voting under mixed electoral rules: evidence from Germany. European Journal of Political Research, 46, 1-23.

Gschwend, T., Johnston, R., \& Pattie, C. (2003). Split-ticket patterns in mixed-member proportional election systems: estimates and analyses of their spatial variation at the German federal election, 1998. British Journal of Political Science, 33, 109-27.

Hainmueller, J., \& Kern, H. L. (2008). Incumbency as a source of spillover effects in mixed electoral systems: evidence from a regression-discontinuity design. Electoral Studies, 27, 213-227.

Herrmann, M., \& Pappi, F. U. (2008). Strategic voting in German constituencies. Electoral Studies, 27, 228 244.

Hoffman, D. T. (1982). A model for strategic voting. SIAM Journal on Applied Mathematics, 42(4), 751-761.

Johnston, R. J., \& Pattie, C. J. (1991). Tactical voting in Great Britain 1983 and 1987: an alternative approach. British Journal of Political Science, 21, 95-108.

Katz, J. N., \& King, G. (1999). A statistical model for multiparty electoral data. American Political Science Review, 93, 15-32.

King, G., Tomz, M., \& Wittenberg, J. (2000). Making the most of statistical analyses: improving interpretation and presentation. Amercan Journal of Political Science, 44, 341-355.

Levitt, S. D., \& Wolfram, C. D. (1997). Decomposing the sources of incumbency advantage in the U.S. House. Legislative Studies Quarterly, 22, 45-60.

McKelvey, R. D., \& Ordeshook, P. C. (1972). A general theory of the calculus of voting. In J. Herndon \& J. Bernd (Eds.), Mathematical applications in political science (pp. 32-78). Charlottesville: University of Virginia Press.

Moser, R. G., \& Scheiner, E. (2005). Strategic ticket-splitting and the personal vote in mixed-member electoral systems. Legislative Studies Quarterly, 30, 259-276.

Myatt, D. P. (2007). On the theory of strategic voting. Review of Economic Studies, 74(1), 255-281.

Myatt, D. P., \& Fisher, S. D. (2002). Everything is uncertain and uncertainty is everything. Department of Economics Discussion Paper No. 115. University of Oxford. 
Myerson, R. B., \& Weber, R. J. (1993). A theory of voting equilibria. American Political Science Review, 87, $102-114$.

Niemi, R. G., Whitten, G., \& Franklin, M. N. (1992). Constituency characteristics, individual characteristics and tactical voting in the 1987 British General Election. British Journal of Political Science, 22, 229 247.

Ordeshook, P. C., \& Zeng, L. (1997). Rational voters and strategic voting: evidence from the 1968, 1980 and 1992 elections. Journal of Theoretical Politics, 9, 167-187.

Palfrey, T. R. (1989). A mathematical proof of Duverger's law. In P. C. Ordeshook (Ed.), Models of strategic choice in politics (pp. 69-91). Ann Arbor: University of Michigan Press.

Pappi, F. U., \& Thurner, P. W. (2002). Electoral behaviour in a two-vote system: incentives for ticket splitting in German Bundestag elections. European Journal of Political Research, 41, 207-32.

Persson, T., Roland, G., \& Tabellini, G. (2007). Electoral rules and government spending in parliamentary democracies. Quarterly Journal of Political Science, 2, 155-188.

Powell, B. (2000). Elections as instruments of democracy. Majoritarian and proportional visions. New Haven: Yale University Press.

Reed, S. R. (1990). Structure and behaviour: extending Duverger's law to the Japanese case. British Journal of Political Science, 20, 335-356.

Reed, S. R. (1999). Strategic voting in the 1996 Japanese general election. Comparative Political Studies, 32, 257-270.

Rietz, T. A., Myerson, R. B., \& Weber, R. J. (1998). Campaign finance levels as coordinating signals in three-way experimental elections. Economics and Politics, 10, 185-217.

Roberts, G. K. (1988). The "second-vote" campaign strategy of the West German Free Democratic Party. European Journal of Political Research, 16, 317-337.

Schoen, H. (1999). Split-ticket voting in German federal elections, 1953-1990: an example of sophisticated balloting? Electoral Studies, 18, 473-496.

Shikano, S., Herrmann, M., \& Thurner, P. W. (2009). Strategic voting under proportional representation: threshold insurance in German elections. West European Politics, 32, 630-652.

Statistisches Bundesamt (various years), Die Wahlbewerber fnr die Wahl zum Deutschen Bundestag, SFG, Servicecenter Fachverlag.

Upton, G. J. G. (1994). Picturing the 1992 British General election. Journal of the Royal Statistical Society, 157, 231-252.

Warwick, P. V. (1994). Government survival in parliamentary democracies. Cambridge: Cambridge University Press. 